\title{
Using high resolution DSM data to correct the terrain illumination effect in Landsat data
}

\author{
F. Li ${ }^{a}$, D. L. B. Jupp ${ }^{b}$, M. Thankappan ${ }^{a}$ \\ ${ }^{a}$ National Earth Observation Group, Geoscience Australia, GPO Box 378, ACT, 2601, Australia \\ Email: Fuqin.Li@ga.gov.au \\ Medhavy.Thankappan@ga.gov.au \\ ${ }^{b}$ CSIRO, Marine and Atmospheric Research, GPO Box 3023, ACT 2601, Australia \\ David.Jupp@csiro.au
}

\begin{abstract}
Terrain affects optical satellite images through both irradiance and bidirectional reflectance distribution function (BRDF) effects. Slopes facing the sun receive enhanced solar irradiance and appear brighter compared to those facing away from the sun. For anisotropic surfaces, the radiance received at the satellite sensor from a sloping surface is also affected by surface BRDF which varies with combinations of surface landcover types, sun, and satellite geometry (sun and sensor view, and their relative azimuth angle) as well as topographic geometry (primarily slope and aspect angles). Consequently, to obtain comparable surface reflectance from satellite images covering mountainous areas, it is necessary to process the images to reduce or remove the topographic effect so that the images can be used for different purposes on the same spectral base. The most common method of normalising for the topographic effect is by using a Digital Surface Model (DSM) and / or a Digital Elevation Model (DEM). However, the accuracy of the correction depends on the accuracy, scale and spatial resolution of DSM data as well as the co-registration between the DSM and satellite images. A physics based BRDF and atmospheric correction model in conjunction with the 1-second SRTM (Shuttle Radar Topographic Mission) derived DSM product released by Geoscience Australia in 2010 were used to conduct the analysis reported in this paper.

The results show that artefacts in the DSM data can cause significant local errors in the correction. For some areas, false shadow and over corrected surface reflectance factors have been observed. In other areas, the algorithm is unable to detect shadow or retrieve an accurate surface reflectance factor in the slopes away from the sun. The accuracy of co-registration between satellite images and DSM data is important for the topographic correction. A mis-registration error of one or two pixels can lead to large error of retrieved surface reflectance factors in the gully and ridge areas (retrieved reflectance factors can change from 0.3 to 0.5 or more). Therefore, accurate registrations for both satellite images and DSM data are necessary to ensure the accuracy of the correction. Using low resolution DSM data in conjunction with high resolution satellite images can fail to correct some significant terrain effects. A DSM resolution appropriate to the scale of the resolution of satellite image is needed for the best results.
\end{abstract}

Key words: DSM, Satellite images, Topographic correction. 


\section{INTRODUCTION}

Topographic correction of satellite images over mountainous or hilly areas is very important (Liang, 2002). Hill and mountain terrain affects optical satellite images through both irradiance and BRDF effects (Dymond et al., 2001). Slopes facing toward the sun receive more solar irradiance and appear brighter in satellite images than those facing away from the sun (Shepherd and Dymond, 2003). For anisotropic surfaces, the radiance received at the satellite from sloping surfaces is also affected by surface BRDF which results from surface landcover structure interacting with the sun and satellite geometry (sun and view and its relative azimuth angle) as well as topographic geometry (e.g. slope and aspect angles). All of these affect the inversion of land surface parameters and applications that aim to detect land surface change through time series analysis.

The availability of good quality Digital Surface Models (DSMs) and Digital Elevation Models (DEMs) to the public enables the routine application of topographic correction. A variety of advanced topographic correction algorithms based on DSM/DEM data have been developed (Teillet et al., 1982, Richter, 1997 and Shepherd and Dymond, 2003, Li et al., 2010a). However, for the DSM/DEM based algorithms, the accuracy of the correction depends on the accuracy of the DSM data, its spatial resolution and scale, and the unavoidable levels of mis-registration between the DSM and satellite data. In this study, the impact of DSM on the topographic correction of satellite data was investigated.

\section{METHOD SELECTED FOR THE STUDY}

A physics based coupled BRDF and atmospheric model for both flat (horizontal) and rugged surfaces developed by Li et al. (2010a) is used in this study.

For anisotropic surfaces over mountainous or hills area, the radiative transfer model from Li et al., (2010a) can be expressed as:

$$
L_{T O A}=L_{0}+\frac{T_{V}}{\pi}\left(E^{\operatorname{dir}}\left[f_{V} \rho_{S}\left(i_{t}, e_{t}, \delta \varphi_{t}\right)+\left(1-f_{V}\right) \overline{\rho^{\prime}}\left(i_{t}\right)\right]+E^{d i f}\left[f_{V} \bar{\rho}\left(e_{t}\right)+\left(1-f_{V}\right) \overline{\bar{\rho}}\right]+E \frac{S(\overline{\bar{\rho}})^{2}}{1-S \overline{\bar{\rho}}}\right)
$$

Where $\mathrm{L}_{\mathrm{TOA}}$ is sensor radiance, $\mathrm{L}_{0}$ is path radiance, $\mathrm{T}_{\mathrm{V}}$ is total transmittance in the view direction, $\mathrm{E}, \mathrm{E}^{\mathrm{dir}}$ and $\mathrm{E}^{\mathrm{dif}}$ are total irradiance, direct component of irradiance and diffuse component of irradiance on a sloping surface, respectively, $i_{t}$ and $e_{t}$ are incident and exiting zenith angles between the sun and view directions and surface normal, $\delta \varphi_{\mathrm{t}}$ is the relative azimuth angle between incident and exiting directions in the slope geometry and $\delta \varphi_{\mathrm{t}}=\left|\varphi_{\mathrm{i}}-\varphi_{\mathrm{v}}\right| . \varphi_{\mathrm{i}}$ and $\varphi_{\mathrm{v}}$ are the azimuth angle for incident and exiting direction in the slope geometry, $\bar{\rho}, \overline{\rho^{\prime}}$ and $\overline{\bar{\rho}}$ are surface hemispherical-directional, directional-hemispherical and hemisphericalhemispherical reflectance (or bi-hemispherical) factors, respectively, and $\mathrm{S}$ is atmospheric albedo which is the bi-hemispherical ratio between upwelling radiation from the surface and the downwelling radiation. $f_{V}$ and $\mathrm{f}_{\mathrm{S}}$ are defined as:

$\mathrm{f}_{\mathrm{V}}=\mathrm{t}_{\mathrm{V}} /\left(\mathrm{t}_{\mathrm{V}}+\mathrm{t}_{\mathrm{d}}\left(\theta_{\mathrm{V}}\right)\right)=\mathrm{t}_{\mathrm{V}} / \mathrm{T}_{\mathrm{V}}$ and $\mathrm{f}_{\mathrm{S}}=\mathrm{t}_{\mathrm{S}} /\left(\mathrm{t}_{\mathrm{S}}+\mathrm{t}_{\mathrm{d}}\left(\theta_{\mathrm{S}}\right)\right)=\mathrm{t}_{\mathrm{V}} / \mathrm{T}_{\mathrm{S}}$

Where $t_{S}$ and $t_{V}$ are direct transmittance in the solar and view directions. $t_{d}\left(\theta_{S}\right)$ and $t_{d}\left(\theta_{V}\right)$ are diffuse transmittance in the solar and view directions; $\mathrm{T}_{\mathrm{S}}$ is total transmittance in the sun direction.

\section{STUDY AREAS AND DATA USED}

The Australian Alps and Blue Mountains in New South Wales (NSW) were the two areas selected for this study as these two regions cover some of the highest terrain in Australia.

A clear Landsat 5 image (Path 91 and Row 85) sensed on February 25, 2009 with moderate solar zenith angle $\left(\sim 45^{\circ}\right)$ was used to conduct the analysis. A small subset of the Landsat 5 TM image covering the Australian Alps located in the northeast of Victoria was used. The central geographical location of the area is $36.75^{\circ} \mathrm{S}$ and $146.95^{\circ} \mathrm{E}$. The Australian Alps have the most significant topographic effects in Australia, its elevation is also the highest, reaching $2100 \mathrm{~m}$ above mean sea level.

The Blue Mountains is located in NSW; a clear Landsat 5 image (Path 90 and Row 84) sensed on September 22, 2006 with moderate solar zenith angle $\left(\sim 45^{\circ}\right)$ was selected for the site. A subset of the Landsat 5 TM 
image covering the south of the Blue Mountains was used. The centre coordinates for the area are $33.89^{\circ} \mathrm{S}$ and $150.20^{\circ} \mathrm{E}$.

The ancillary input data needed to run the algorithm included atmospheric water vapour, aerosol optical depth, BRDF parameters as well as the DSM. Atmospheric water vapour was derived from radiosonde data measured by the Australian Bureau of Meteorology. For the Australian Alps, water vapour data were obtained from the Wagga Wagga meteorological station $\left(-35.16^{\circ} \mathrm{S}\right.$ and $\left.147.46^{\circ} \mathrm{E}\right)$, located within the same Landsat scene. For the Blue Mountains area, no radiosonde data was available for locations within the same scene, therefore data from the nearest meteorological station (Wagga Wagga) was used. The total precipitable water content comparison between the NOAA NCEP (National Centers for Environmental Prediction) reanalysis product (Kalnay et al., 1996) and Wagga Wagga radiosonde data shows that they are very close. Since the water vapour has a relatively minor impact on the Landsat visible and shortwave reflectance retrievals, the Wagga Wagga radiosonde data is sufficient to be used in the south of Blue Mountains areas.

The aerosol data were obtained from the local Aeronet station in Canberra (http://aeronet.gsfc.nasa.gov). The geographical location for this station is $149.111^{\circ} \mathrm{E}$ and $-35.271^{\circ} \mathrm{S}$ and was appropriate for use in analysis of both images due to similarity of the atmospheric systems in the study sites.

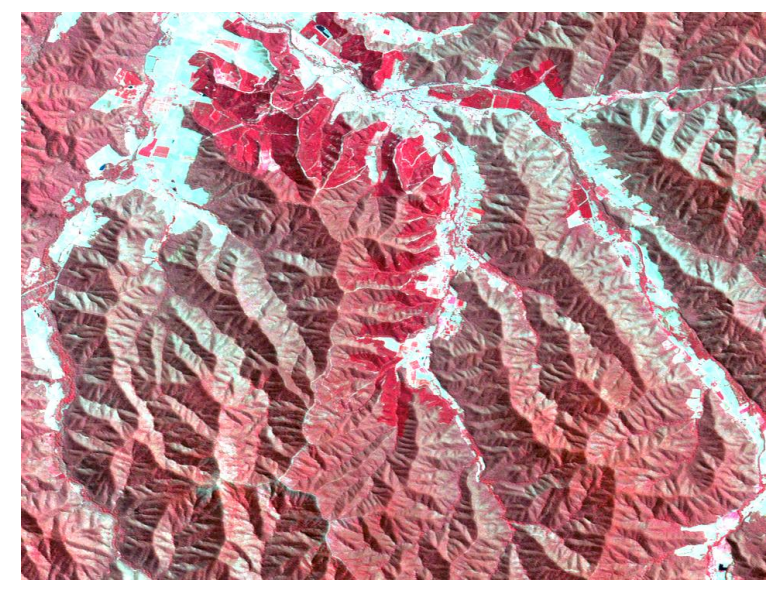

(a)

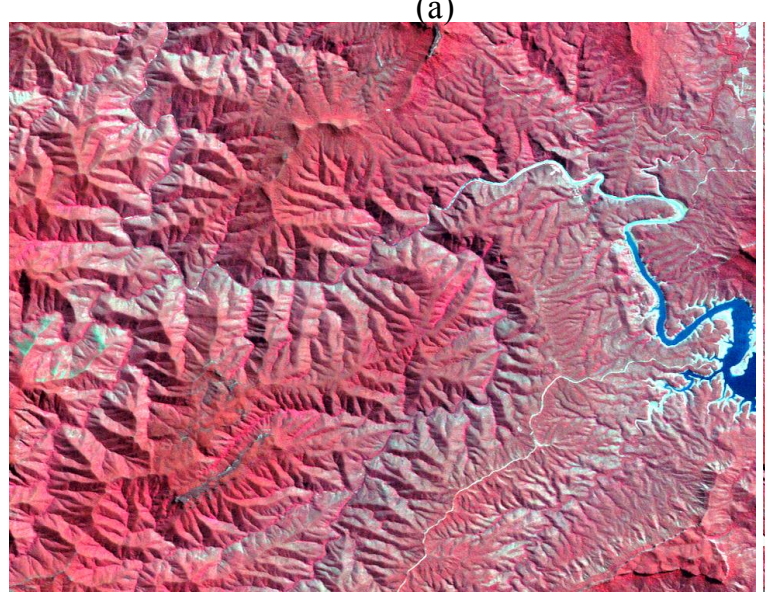

(c)

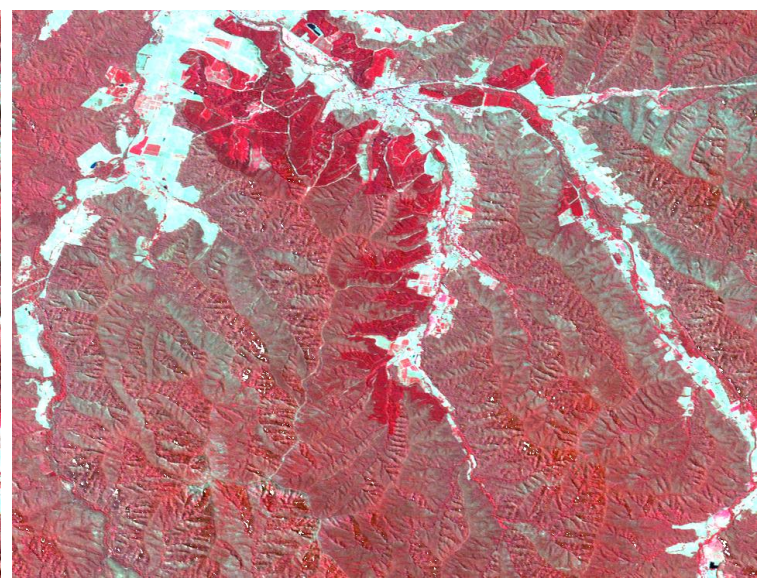

(b)

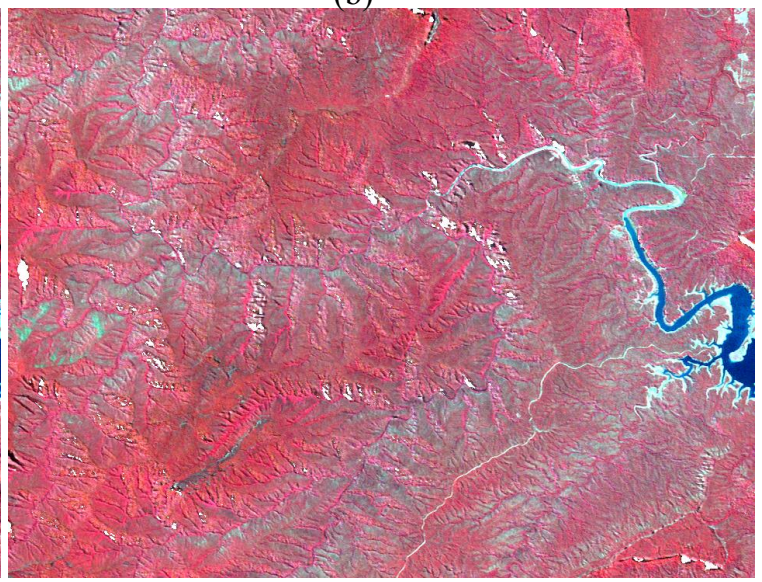

(d)

Figure 1. False colour composite images (bands 4, 3, 2, white colour is detected as shadow): (a) with BRDF and atmospheric correction only for the Victorian Alps image of Feb.25, 2009 (b) with BRDF and atmospheric correction plus topographic correction for the Victorian Alps image of Feb.25, 2009 (c) with BRDF and atmospheric correction only for the south Blue Mountains image of Sept. 22, 2006 (d) with BRDF and atmospheric correction plus topographic correction for the south Blue Mountains image of Sept. 22, 2006.

BRDF parameters were obtained from the MODIS BRDF model product (Schaaf et al., 2002) which is the result of fitting a model to atmospherically corrected MODIS data over a 16-day compositing period. A 
combination of the Ross Thick volume kernel and the Li-sparse Reciprocal (Schaaf et al., 2002) geometric kernel models was used to approximate these data. Following Li et al. (2010b), the BRDF shape is defined for large regions (regional scale); for this study, the average value over the Landsat scene extent was used.

High quality DSM data are very important for physically based terrain illumination correction. Geoscience Australia and CSIRO have released the 1-second Shuttle Radar Topographic Mission (SRTM) derived DSM and DEM of Australia in February, 2010 (Geoscience Australia and CSIRO Land \& Water, 2010). The DSM data are designed to serve different purposes and one of these is where radiation is obstructed by the roughness surface rather than the soil surface. However, we found that DSM data needed to be pre-processed before being applied in terrain correction. Various artefacts in the DSM data, which can have a significant effect on slope and aspect, need be removed or reduced. In this study, the DSM data were first median filtered to remove outliers that seem to occur in SRTM data and have a serious effect on calculations of slope and aspect. It was then smoothed to a minimal level using a 3 by 3 Gaussian filter to remove digitization effects. The digitisation effects are due to SRTM data originally having 1 metre precision. It was then resampled to Landsat resolution using the bilinear method and finally Gaussian smoothed with width of 5 pixels to bring the scale to the level ( 50 metres correlation length) judged best in this case for the correction. The appropriate scale for the correction is hillslope scale rather than at the micro-relief scale and this was taken into account. DSM data were also resampled to match the Landsat resolution and coordinates. To analyse the impact of DSM spatial resolution, the 3-second global SRTM data set (derived from aggregation of the original 1-second SRTM data) was also used. The pre-processing method for the 3 second data was the same as for the 1-second data except for the final re-scaling by the Gaussian filter as the data are already at a much coarser scale than the 1-second data.

Landsat 5 images were provided by the National Earth Observation Group, Geoscience Australia. The Landsat images were orthocorrected with a latitude and longitude (geographic) projection as in Li et al. (2010b) where the BRDF and atmospheric correction algorithm is described.

\section{RESULTS AND DISCUSSION}

Figure 1 shows the terrain corrected results for the two study sites using the 1-second DSM data. The images were processed using two different algorithms: (1) with BRDF and atmospheric correction only and (2) with BRDF and atmospheric correction plus topographic correction. Comparing Figures 1a, b, c, and d, we can clearly see the terrain effect at hillslope scale has been significantly reduced in Figures $1 \mathrm{~b}$ and $1 \mathrm{~d}$ when compared with BRDF and atmospheric correction only (Figures 1a and 1c).

The resolution and quality of DSM data is very important to ensure the accuracy of current terrain correction. The topographic correction error from DSM data included three different types, i.e., error from the DSM artefacts, error from mismatched pixel coordinates between DSM and Landsat images and error from within pixel DSM variation.

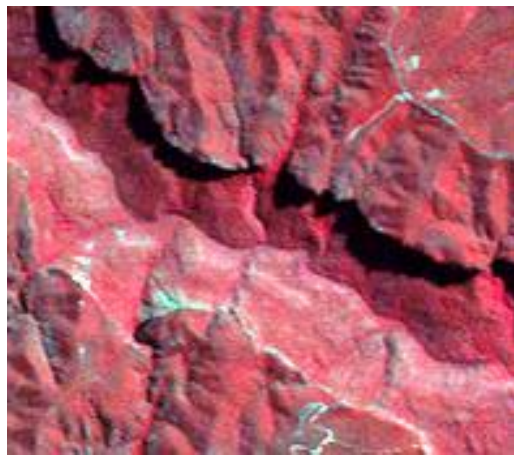

(a)

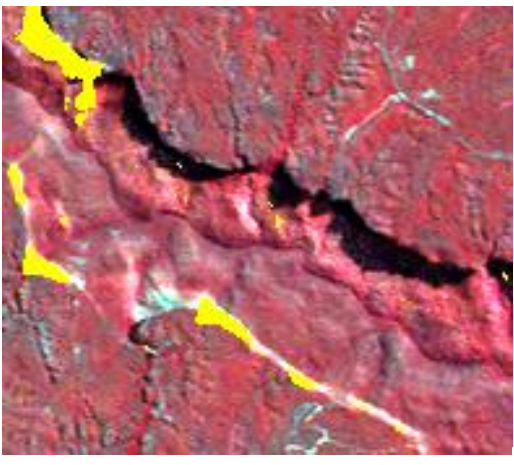

(b)

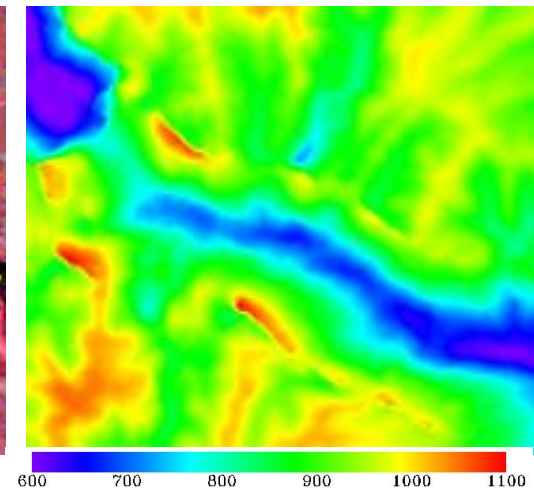

(c)

Figure 2. The impact of DSM data on the accuracy of terrain correction for the south Blue Mountains image of Sept. 22, 2006 (a) False colour composite images (bands 4, 3, 2) with BRDF and atmospheric correction only, (b) False colour composite images (bands 4, 3, 2, yellow colour is detected as shadows) with BRDF and atmospheric correction plus terrain illumination correction, and (c) DSM data of the same area.

In the processing, the DSM data were smoothed to filter out some artefacts (see Section 3). However, this technique could not remove all artefacts. A typical example is in the Blue Mountains area where the SRTM 
radar often could not reach into gorges due to the depression angle. This results in some areas being "filled in" by the radar so that the valleys seem shallow and some areas not having validated DSM data. In such cases, other sources (existing DSMs) were used to fill in the values as in the 1-second DSM product. The consequence is that some bright areas in the original images were even brighter or masked out as computed shadows. By contrast, some dark areas were not masked as shadows or appeared even darker. Figure 2 shows an example of this. Some of the brighter and masked pixels (yellow colour) of Figure $2 b$ are associated with artefacts in the DSM data (Figure 2c). In this area, the DSM creates artificial slopes and shadows while the real shadows are not masked. However, it is impossible to avoid this kind of error until higher quality DSM data sets become available in the future.

Table 1. Comparison of terrain corrected surface reflectance between accurately co-registered Landsat and DSM data, and mis-registered data sets.

\begin{tabular}{|c|c|c|c|}
\hline Slope condition & With BRDF only & $\begin{array}{c}\text { With terrain and } \\
\text { accurate DSM }\end{array}$ & $\begin{array}{c}\text { With terrain and shifted } \\
\text { DSM }\end{array}$ \\
\hline Facing sun & 0.3036 & 0.2701 & 0.4879 \\
\hline Away from sun & 0.1374 & 0.1917 & 0.1291 \\
\hline Away from sun & 0.1545 & 0.1718 & 0.1324 \\
\hline Facing sun & 0.3539 & 0.3069 & 0.5062 \\
\hline Facing sun & 0.2690 & 0.2339 & 0.3772 \\
\hline
\end{tabular}

Mismatch between DSM and Landsat pixel coordinates can cause significant error for the correction, particularly for pixels around the ridges and gully floors. If pixel coordinates between DSM and satellite images are not consistent then sometimes the DSM data may show the pixel to be in the slope away from the sun, whereas, in Landsat, it may be located in a slope facing the sun with relatively large at-sensor radiance. In this case, after correction, the corrected reflectance will be very large. On the other hand, if the DSM has the pixel in the slope facing the sun, but in the Landsat, it is located in the slope away from the sun with small at-sensor radiance, then after correction, the corrected reflectance will be smaller. To test this, we shifted two DSM pixels in the west direction using the September 22, 2006 image to see how the results changed. Table 1 shows some results from five selected pixels which were both facing and away from the sun. The results from Table 1 clearly show how pixel mismatch affects the accuracy of the product. The reflectance factor can change from 0.30 in correctly matched DSM and Landsat data to 0.50 in poorly matched coordinates. In some areas, the difference will be larger than this. The results can also be seen clearly from the images (see Figure 3 ) where the well registered image removed most of the shadow, but the poorly co-registered image did not.

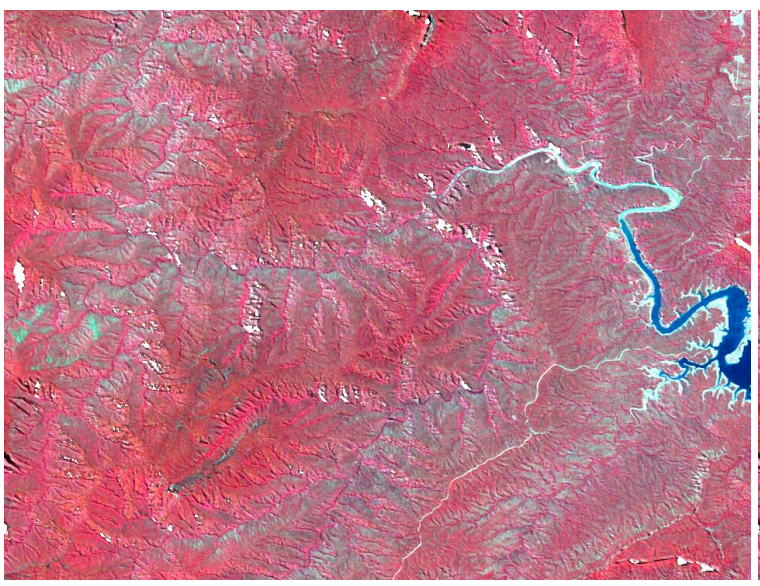

(a)

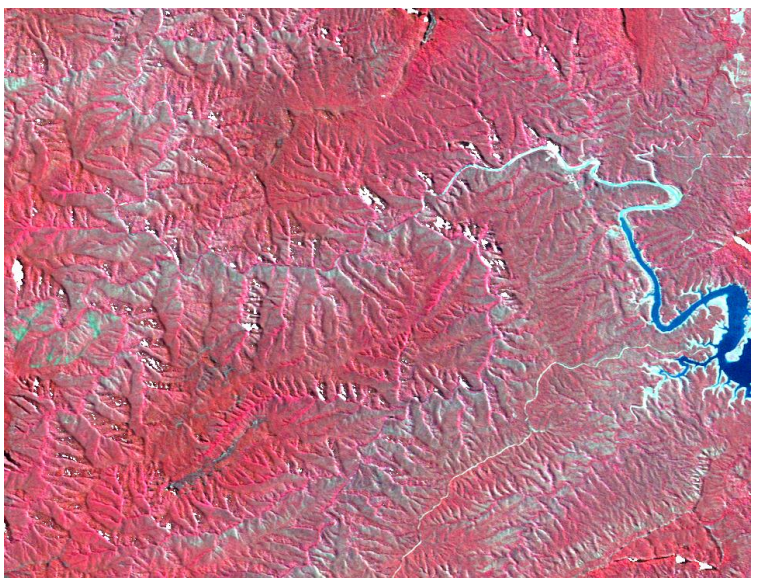

(b)

Figure 3. The impact of co-registration between DSM and Landsat images on the accuracy of terrain correction for the south Blue Mountains site (a) accurate co-registered false colour composite images (bands $4,3,2$, white colour is detected as shadow) (a) mis-registered false colour composite images (bands 4, 3, 2, white colour is detected as shadow). 
For some pixels, although DSM coordinates match perfectly with Landsat coordinates, due to the within pixel DSM variation, in some areas, eg. gully and ridge areas, the reflectance factors can not be fully corrected. As a result, shadows cannot be removed completely in some areas and surface reflectance factors are overcorrected in other areas. In analysing this, we applied the topographic correction algorithm using two different DSM data sets based on the 1-second SRTM data and the 3-second global SRTM data. The same sub area was extracted from the Landsat images. Figure 4 shows the comparison. The figure clearly shows that the 1-second DSM data can remove more shadows (Figure 4a), whereas 3-second DSM removed fewer shadows (Figure 4b). It can be seen from Figure 4 that the 3-second DSM data leaves a residual texture of light and shade that is at the "hillslope" scale. Therefore, the 3-second DSM is too coarse to achieve the accuracy of the correction than the 1-second DSM data. However, more work is needed to test whether the residual shadows from correction using the 3-second DSM affects land cover mapping and other applications. At present, the best SRTM DSM data (1-second) are around $30 \mathrm{~m}$ resolution and Landsat data are also at $30 \mathrm{~m}$ resolution. The 1 -second DSM data are sufficient to correct Landsat data which have similar spatial resolution with DSM for most areas. However, for some areas where terrain variations are at a finer spatial resolution, it is difficult to remove shadows using the 1-second DSM data and Landsat data. In some areas, the coarse resolution of both DSM and Landsat data result in a larger value for the calculated slope angle, this could imply low or no radiation from the sun. However, there is still a large amount solar radiation incident within the extent of the pixel on account of finer terrain variations within the slope. Therefore, overcorrection can not be avoided in this situation. Whether better than 1-second DSM data, or a modified algorithm, can improve the accuracy of correction for the terrain variations at a finer resolution and high resolution satellite images needs further investigation.

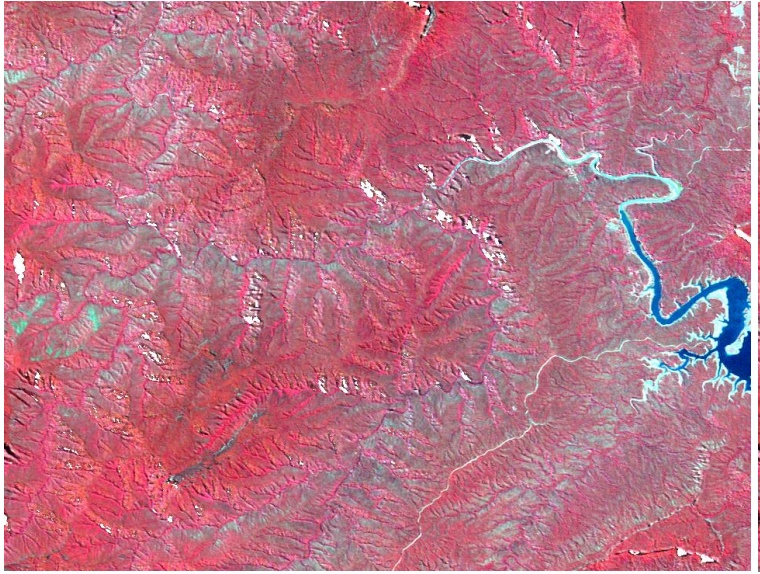

(a)

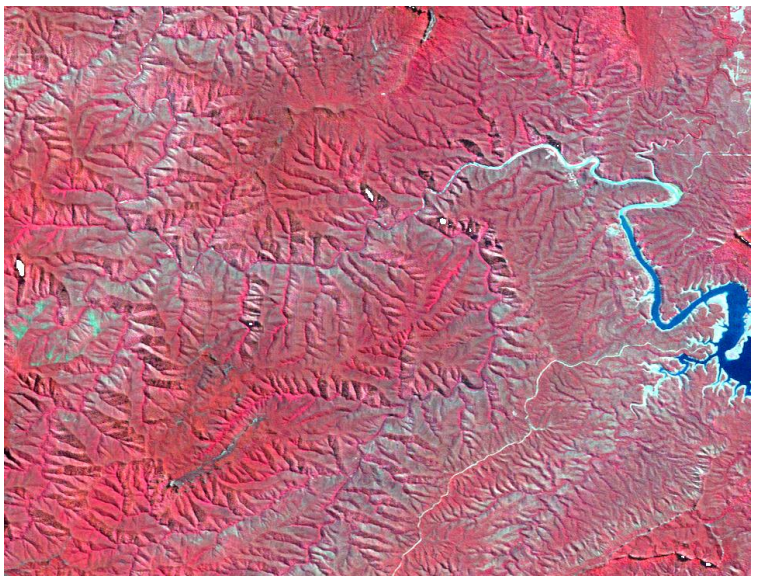

(b)

Figure 4. The impact of DSM spatial resolution on the accuracy of terrain correction for the south Blue Mountains site (a) using 1-second DSM data (a) using 3-second DSM.

\section{CONCLUSIONS}

A physics based coupled BRDF and atmospheric correction model can be applied to both flat and inclined surfaces and has been shown to reduce most of the BRDF, atmospheric and topographic effects at the scale of Landsat data. However, the accuracy of the DSM based topographic correction method depends on the quality of DSM data, its co-registration with Landsat data as well its spatial resolution.

The presence of artefacts in DSM data can cause significant error in the terrain correction process. On one hand, it results in false shadows and over corrected surface reflectance factors. On the other, it is unable to detect the shadow and retrieve reflectance in the slopes away from the sun. Fortunately, these errors tend to be localised and easy to identify.

The accuracy of co-registration between satellite and DSM data is important for the topographic correction of satellite images. Mis-registration by one or two pixels can lead to large errors in the gully and ridge areas. Therefore, accurate registration of satellite images and DSM data are necessary to ensure the accuracy of the correction. As SRTM registration may be near a half pixel compared with GPS, this will probably require that terrain-corrected products be based on precision processed, ortho-corrected images rather than current standard precision images. 
The use of low resolution DSM data to correct high resolution satellite images does not provide as high quality results as using the high resolution DSM. However, further investigation is needed to establish how the residual shadows from using a lower resolution DSM will affect landcover mapping or other time series applications of surface reflectance data. But it is clear that DSM data at a scale appropriate for the satellite data and the scale of hillslopes modifying the irradiance are necessary to correct high resolution satellite images.

\section{ACKNOWLEDGEMENT}

The authors acknowledge Geoscience Australia for the provision of Landsat images and DSM data. MODIS BRDF model parameters were downloaded from the NASA MODIS website. Sun photometer data were from the NASA AERONET site and radiosonde data and precipitable water were obtained from NOAA. Advice provided by Dr Leo Lymburner and Mr Norman Mueller regarding the quality DSM data and topographic correction results is gratefully acknowledged. Authors would also like to thank Mr Lan-wei Wang and $\mathrm{Mr}$ Peter Tan for reviewing the paper. This paper has been published with the permission of the CEO, Geoscience Australia.

\section{REFERENCES}

Dymond, J.R., Shepherd, J.D. and Qi, J., 2001, A simple physical model of vegetation reflectance for standardising optical satellite imagery. Remote Sensing of Environment, 77: 230-239

Geoscience Australia and CSIRO Land \& Water (2010) 1 Second SRTM Derived Digital Elevation Models User Guide. Version 1.0. Geoscience Australia.

Kalnay, E., Kanamitsu, M., Kistler, R., Collins, W., Deaven, D., Gandin, L., Iredell, M., Saha, S., White, G, Woollen, J, Zhu, Y., Chelliah, M, Ebisuzaki, W., Higgins, W., Janowiak, J., Mo, K.C., Ropelewski, C., Wang, J., Leetmaa, A., Reynolds, R., Jenne, R. and Joseph, D., 1996, The NCEP/NCAR 40-Year Reanalysis Project. Bulletin of the American Meteorological Society, 77: 437-471

Liang, S., 2002. Quantitative Remote Sensing of Land Surface. Wiley-Interscience, 534pp.

Li, F., Wang, L. and Jupp, D. L. B., 2010a. A processing system for generating standard nadir BRDF adjusted surface reflectance (NBAR) products for Landsat. The 15th Australasian Remote Sensing and Photogrammetry Conference, Alice Spring, 2010.

Li, F., Jupp, D. L. B., Reddy, S., Lymburner, L., Mueller, N.,Tan, P. and Islam, A., 2010b, An evaluation of the use of atmospheric and BRDF correction to standardize Landsat data. The IEEE Journal of Selected Topics in Applied Earth Observations and Remote Sensing, 3:257-270

Richter, R., 1997. Correction of atmospheric and topographic effects for high spatial resolution satellite imagery', International Journal of Remote Sensing, 18: 5, 1099- 1111

Schaaf, C., Gao, F., Strahler, A.H., Lucht, W., Li, X., Tsang, T., Strugnell, N.C., Zhang, X., Jin, Y., Muller, J.-P, Lewis, P., Barnsley, M., Hobson, P., Disney, M., Roberts, G., Dunderdale, M., Doll, C., d'Entremont, R.P., Hu, B., Liang, S., Privette, J.L. and Roy, D., 2002, First operational BRDF, albedo and nadir reflectance products from MODIS. Remote Sensing of Environment, 83: 135-148.

Shepherd, J.D. and Dymond, J.R., 2003. Correcting satellite imagery for the variance of reflectance and illumination with topography. International Journal of Remote Sensing, 24: 3503-314

Teillet, P.M, Guindon, B. and Goodenough, D.G., 1982. On the slope-aspect correction of multispectral scanner data. Canadian Journal of Remote Sensing, 8: 84-106 